\title{
Double Tungstate Lasers: From Bulk Toward On-Chip Integrated Waveguide Devices
}

\author{
Markus Pollnau, Yaroslav E. Romanyuk, Florent Gardillou, Camelia N. Borca, Uwe Griebner, Simon Rivier, \\ and Valentin Petrov \\ (Invited Paper)
}

\begin{abstract}
It has been recognized that the monoclinic double tungstates $\mathrm{KY}\left(\mathrm{WO}_{4}\right)_{2}, \mathrm{KGd}\left(\mathrm{WO}_{4}\right)_{2}$, and $\mathrm{KLu}\left(\mathrm{WO}_{4}\right)_{2}$ possess a high potential as rare-earth-ion-doped solid-state laser materials, partly due to the high absorption and emission cross sections of rare-earth ions when doped into these materials. Besides, their high refractive indexes make these materials potentially suitable for applications that require optical gain and high power in integrated optics, with rather high integration density. We review the recent advances in the field of bulk lasers in these materials and present our work toward the demonstration of waveguide lasers and their integration with other optical structures on a chip.
\end{abstract}

Index Terms-CW lasers, dielectric materials, dielectric waveguides, epitaxial layers, integrated optics, ion implantation, optical waveguides, optical planar waveguides, optical strip waveguides, pulsed lasers, rare earth compounds, solid lasers, thulium compounds, tungsten compounds, ytterbium compounds.

\section{INTRODUCTION}

W ITHIN THE PAST five decades since their invention, solid-state lasers have become the working tools in many areas of applications. There is a drive for extended wavelength diversity, ever increasing output powers, shorter pulses, improved wall-plug efficiencies, as well as the need for smaller footprint and higher optical integration. With respect to these demands, in recent years, the family of monoclinic potassium double tungstates has received a lot of attention as highly suitable rare-earth-ion-doped laser host materials.

The potassium double tungstates $\mathrm{KY}\left(\mathrm{WO}_{4}\right)_{2}(\mathrm{KYW})$, $\mathrm{KGd}\left(\mathrm{WO}_{4}\right)_{2}(\mathrm{KGdW})$, and $\mathrm{KLu}\left(\mathrm{WO}_{4}\right)_{2}(\mathrm{KLuW})$ are isostructural and strongly anisotropic biaxial crystals, which crystallize in the monoclinic structure with space group $C 2 / c$ [1]-[4]. A summary of some of their physical characteristics [unit cell parameters, density, melting and crystallization temperature, hard-

Manuscript received November 15, 2006. This work was supported in part by the European Union under Project DT-CRYS and in part by the Swiss National Science Foundation.

M. Pollnau is with the Integrated Optical Micro Systems Group, MESA+ Research Institute, University of Twente, NL-7500 AE Enschede, The Netherlands (e-mail: m.pollnau@ewi.utwente.nl).

Y. E. Romanyuk is with Lawrence Berkeley National Laboratory, Berkeley, CA 94720 USA (e-mail: yaroslav.romanyuk@gmail.com).

F. Gardillou is with Teem Photonics S.A., F-38240 Meylan, France (e-mail: f.gardillou@teemphotonics.com).

C. N. Borca is with Paul Scherrer Institut, CH-5232 Villigen, Switzerland (e-mail: camelia.borca@psi.ch).

U. Griebner, S. Rivier, and V. Petrov are with Max-Born-Institute for Nonlinear Optics and Ultrafast Spectroscopy, D-12489 Berlin, Germany (e-mail: griebner@mbi-berlin.de; rivier@mbi-berlin.de; petrov@mbi-berlin.de).

Digital Object Identifier 10.1109/JSTQE.2007.896094 ness, and stimulated Raman scattering (SRS)-active vibration modes] can be found in [5] and [6]. Many laser relevant properties like refractive index, optical transparency, and thermal conductivity are very similar for the three undoped monoclinic double tungstates [5], [6]. They exhibit one of the largest absorption and emission cross sections and broader linewidths when doped with rare-earth ions, which may be partly due to the high refractive indexes and partly due to the strong anisotropy [7], [8]. Another important advantage of the rare-earth-ion-doped monoclinic potassium double tungstates is the relatively large ion separation allowing highest doping levels with minimum quenching effects.

In this paper, we review the recent advances in the field of $\mathrm{Yb}$ and Tm bulk lasers based on monoclinic double tungstates $\mathrm{KYW}$, KGdW, and KLuW, and present our work toward the demonstration of waveguide lasers and their integration with other optical structures on a chip. Section II deals with bulk laser performance in these materials. The growth of KYW thin layers and planar waveguide fabrication is described in Section III, and laser results obtained with these waveguides are discussed in Section IV. Finally, the fabrication of channel waveguides and the first integrated optical structures in KYW is described in Section V.

\section{BULK LASERS}

Among the rare-earth-ion-doped solid-state materials, $\mathrm{Yb}^{3+}$ doped crystals are in particular well suited as gain media in highpower lasers, femtosecond lasers, and amplifiers [9]. $\mathrm{Yb}^{3+}$ is a promising activating ion that possesses a number of advantages over $\mathrm{Nd}^{3+}$ for laser operation in the $1-\mu \mathrm{m}$ spectral region [10]. These advantages are related to the very simple energy level scheme constituted of only two levels: the ${ }^{2} \mathrm{~F}_{7 / 2}$ ground state and the ${ }^{2} \mathrm{~F}_{5 / 2}$ excited state. Effects such as excited-state absorption, cross relaxation, and energy-transfer upconversion, which can lead to a reduced laser efficiency through alternative paths for depopulation of the upper laser level, are absent. The $\mathrm{Yb}^{3+}$ ion also has a small quantum defect as a result of the close pump and laser wavelengths, leading to a low thermal load. The most intense $\mathrm{Yb}^{3+}$ absorption line near $980 \mathrm{~nm}$ is suitable for pumping with InGaAs laser diodes. The thermal conductivity of the double tungstates of approximately $3.3 \mathrm{~W} \mathrm{~m}^{-1} \mathrm{~K}^{-1}$ (averaged over the polarizations) is about three times lower than in YAG but four times that of a typical phosphate laser glass [11].

The $\mathrm{Yb}^{3+}$-doped double tungstates $\mathrm{KGdW}: \mathrm{Yb}^{3+}$, $\mathrm{KYW}: \mathrm{Yb}^{3+}$, and the novel KLuW: $\mathrm{Yb}^{3+}$ (for a review, see [12]) 
have been recognized as laser materials with a high potential for efficient tunable continuous-wave (CW) and mode-locked operation in diode-pumped arrangements [7], [8], [11], [13]-[16].

End-pumping schemes in most cases offer a compact and inexpensive laser design in which matching the pump and laser modes can be relatively easy. This is an important issue considering the three-level nature and corresponding reabsorption in $\mathrm{Yb}^{3+}$ transitions around $1 \mu \mathrm{m}$. The highest slope efficiencies have been reported for end-pumped configurations [13], [14]. End-pumped configurations are also more favorable for compact lasers or Q-switched lasers with short pulse lengths than are the multipass thin-disk configurations. Recent analysis by Brenier and Boulon [17] and Brenier [18] reveals that KYW and $\mathrm{KGdW}$ (at that time $\mathrm{KLuW}$ was still not introduced) should be the most promising $\mathrm{Yb}^{3+}$ hosts for end-pumped $\mathrm{CW}$ lasers. This conclusion stems primarily from the calculations of the laser output yield (or optical efficiency) and slope efficiency.

The most efficient end-pumped laser configuration reported appears to be the pumping of KGdW: $\mathrm{Yb}^{3+}$ and $\mathrm{KYW}: \mathrm{Yb}^{3+}$ by a gain-switched $\mathrm{Al}_{2} \mathrm{O}_{3}: \mathrm{Ti}^{3+}$ laser [14]. In this setup, the slope efficiency reached $\sim 87 \%$ and the output yield was around $50 \%$. Under diode pumping, the highest efficiency was achieved using a 3-mm-thick KLuW: $\mathrm{Yb}^{3+}$ sample with $5 \% \mathrm{Yb}^{3+}$ doping, mounted in a water-cooled $\mathrm{Cu}$ block and placed in a two-mirror cavity. The fiber-coupled diode emission at $980 \mathrm{~nm}$ was focused to a spot radius of $\sim 40 \mu \mathrm{m}$. The most efficient CW laser operation resulted in an output power of $3.28 \mathrm{~W}$ for an incident pump power of $6.8 \mathrm{~W}$. Here, slope efficiencies reached $78 \%$ and the optical efficiency was around 50\% [16]. Power scaling was studied using $\mathrm{KGdW}: \mathrm{Yb}^{3+}$ under end-pumping with highpower diode bars [19]. A CW output power of $12.4 \mathrm{~W}$ for $26 \mathrm{~W}$ of incident pump power with an optical-to-optical efficiency of $47 \%$ was achieved using a fiber-coupled pump source. The slope efficiency at this power level was $74 \%$ with respect to incident pump power. The limit to the power scalability is reached due to thermal fracture of the laser crystal at the heat fluence of $33 \mathrm{~kW} / \mathrm{cm}^{2}$.

The $\mathrm{Yb}^{3+}$ ion in KGdW, KYW, and KLuW has an absorption maximum near $981 \mathrm{~nm}$ with a cross section, for polarization parallel to the $N_{\mathrm{m}}$ principal optical axis, about 15 times larger than that of YAG: $\mathrm{Yb}^{3+}$. Connected with the capability to adopt very high concentrations of $\mathrm{Yb}^{3+}$ reaching the stoichiometric structure $\mathrm{KYb}\left(\mathrm{WO}_{4}\right)_{2}(\mathrm{KYbW})$ [20], extremely short absorption length, substantially below $100 \mu \mathrm{m}$, can be realized. The maximum absorption cross section of $\mathrm{KYbW}$ for light polarization parallel to the crystallo-optic $N_{\mathrm{m}}$ axis of $11.7 \times 10^{-20} \mathrm{~cm}^{2}$ near $981 \mathrm{~nm}$ corresponds to an absorption length of only $13.3 \mu \mathrm{m}$. The first CW laser operation of a stoichiometric $\mathrm{Yb}^{3+}$ laser crystal was achieved with KYbW. The emission wavelength of the KYbW laser was $1068 \mathrm{~nm}$ when pumping at $1025 \mathrm{~nm}$. An output power of $20 \mathrm{~mW}$ was obtained at room temperature [21]. An extremely small quantum defect for an optically pumped laser crystal of only $1.6 \%$ could be demonstrated at room temperature, using a $125-\mu \mathrm{m}$-thin platelet of $\mathrm{KYbW}$. While pumping at $1025 \mathrm{~nm}$, lasing occurred at $1042 \mathrm{~nm}$ [22]. Such highly $\mathrm{Yb}^{3+}$ doped materials are potentially interesting for the thin-disk laser concept [23], which profits from the relaxed requirements to the pump-laser beam quality and the possibility for efficient transverse cooling, in particular in the high-power regime.

When pumping at wavelengths above the center of gravity of the fluorescence curve, one can achieve radiation cooling from that part of the excitation that decays by fluorescence. $\mathrm{Yb}^{3+}$-doped tungstates were actually proposed as optimum materials for radiation-balanced lasers, where radiation cooling compensates the heating from intraband (vibrational) and nonradiative decay [24]. On the other hand, it was shown that when pumped near $930 \mathrm{~nm}, \mathrm{KYW}$ :Yb can efficiently operate as a laser at $981 \mathrm{~nm}[25]$.

With monoclinic $\mathrm{Yb}^{3+}$-doped double tungstates, some of the most promising results with respect to femtosecond generation have been obtained. For the novel KLuW: $\mathrm{Yb}^{3+}$, the shortest pulses obtained by mode-locking with a semiconductor saturable absorber mirror (SESAM) were achieved [26]. The laser generates transform-limited pulses with durations as short as $81 \mathrm{fs}\left(\mathrm{Al}_{2} \mathrm{O}_{3}: \mathrm{Ti}^{3+}\right.$-laser-pumped) and $117 \mathrm{fs}$ (diode-pumped), at a repetition rate of $95 \mathrm{MHz}$ and average output powers of 70 and $23 \mathrm{~mW}$, respectively. The obtained pulse durations are slightly longer than the 71 fs once obtained with a Kerr lens modelocked KYW: $\mathrm{Yb}^{3+}$ laser [27], but shorter than the $\sim 100$ fs reported for SESAM-mode-locked KGdW: $\mathrm{Yb}^{3+}$ and KYW:Yb ${ }^{3+}$ lasers [28], [29].

Output powers on the order of $1 \mathrm{~W}$ were demonstrated from end-pumped KGdW: $\mathrm{Yb}^{3+}$ lasers in the mode-locked regime [30], [31]. Recently, also using KGdW: $\mathrm{Yb}^{3+}$ more than 5 and $10 \mathrm{~W}$ of output power were reported with pulse durations of 134 and 433 fs, respectively. End-pumped by two 23-W laser diodes at $981 \mathrm{~nm}$, the oscillator operates at $45 \mathrm{MHz}$ [32]. Using $\mathrm{KYW}: \mathrm{Yb}^{3+}$, the highest average power $(22 \mathrm{~W})$ from an $\mathrm{Yb}^{3+}$ doped tungstate-based oscillator in the sub-300-fs range was achieved applying the thin-disk laser concept [33]. The highest average power with a femtosecond regenerative amplifier was also obtained using a thin disk of $\mathrm{KYW}: \mathrm{Yb}^{3+}$ that produced $9-\mu \mathrm{J}$ pulses with a duration of $280 \mathrm{fs}$ at a repetition rate of $200 \mathrm{kHz}$ [34]. Cavity-dumped femtosecond oscillators with more than $1-\mu \mathrm{J}$ pulse energy at $1 \mathrm{MHz}$ based on $\mathrm{KYW}: \mathrm{Yb}^{3+}$ were also demonstrated [35].

In addition to being promising host media for rare-earth ions, the monoclinic potassium double tungstates also possess large nonlinear optical susceptibility $\chi^{(3)}$, making them efficient frequency converters through SRS [5]. The energies of the strongest vibrational modes of tungstates are 757 and $908 \mathrm{~cm}^{-1}$ for $\mathrm{KYbW}, 768$ and $901 \mathrm{~cm}^{-1}$ for $\mathrm{KGdW}, 767.4$ and $905.6 \mathrm{~cm}^{-1}$ for KYW [36], and 757 and $907 \mathrm{~cm}^{-1}$ for KLuW [5]. SelfRaman frequency conversion has been demonstrated in diode-pumped Q-switched lasers based on both $\mathrm{KYW}: \mathrm{Yb}^{3+}$ and KGdW: $\mathrm{Yb}^{3+}$ crystals [37]-[39]. A compact diode-pumped $\mathrm{KLuW}: \mathrm{Yb}^{3+}$ laser that operated efficiently in the passively Q-switched mode with simultaneous SRS self-conversion was also reported [16]. Passively Q-switched operation was realized by employing a YAG: $\mathrm{Cr}^{4+}$ saturable absorber resulting in 1030.6-nm fundamental pulses of $1.41 \mathrm{~ns}$ (duration), $32.4 \mu \mathrm{J}$ (energy), and $23 \mathrm{~kW}$ (peak power), and 1137.6-nm Raman pulses of $0.71 \mathrm{~ns}$ (duration), $14.4 \mu \mathrm{J}$ (energy), and $15.2 \mathrm{~kW}$ (peak power). The average output power reached $0.9 \mathrm{~W}$ for the 
fundamental and $0.4 \mathrm{~W}$ for the Raman radiation with optical efficiencies of $12.9 \%$ and $5.7 \%$, and slope efficiencies of $32.1 \%$ and $14.1 \%$, respectively.

Besides $\mathrm{Yb}^{3+}$ doping, the monoclinic double tungstates have advantages for highly efficient, low-threshold laser operation under diode pumping also for $\mathrm{Tm}^{3+}$ doping. In the latter case, the absorption line is centered near $800 \mathrm{~nm}$ [40] with a broader longwave wing. Therefore, these crystals are better suited for pumping with commercially available AlGaAs laser diodes at room temperature than YAG or YLF. The first demonstration of $\mathrm{Tm}^{3+}$ lasing on the ${ }^{3} \mathrm{~F}_{4} \rightarrow{ }^{3} \mathrm{H}_{6}$ transition in monoclinic double tungstates was realized in 1997 with Xe-flash-lamp pumping, where KYW:Tm ${ }^{3+}$ and $\mathrm{KGdW}: \mathrm{Tm}^{3+}$ rods sensitized with $\mathrm{Er}^{3+}$ and $\mathrm{Yb}^{3+}$ operated at cryogenic temperatures and wavelengths of 1920 and $1930 \mathrm{~nm}$, respectively [41]. Soon afterwards, CW room-temperature operation of KYW: $\mathrm{Tm}^{3+}$ was demonstrated with longitudinal $\mathrm{Al}_{2} \mathrm{O}_{3}: \mathrm{Ti}^{3+}$-laser pumping near $800 \mathrm{~nm}$ [40]. Codoping of KYW: $\mathrm{Tm}^{3+}$ with $\mathrm{Yb}^{3+}$ for InGaAs diode pumping at $980 \mathrm{~nm}$ with subsequent excitation transfer was studied in [42], but laser experiments revealed no practical advantages as compared to direct $~ 800-n m$ pumping by AlGaAs diodes [43]. Passive Q-switching and Raman self-conversion to $2365 \mathrm{~nm}$ has also been demonstrated in such lasers [44]. The $\mathrm{Tm}^{3+}$ ion in $\mathrm{KYW}$ or in $\mathrm{KYb}_{0.5} \mathrm{Y}_{0.43} \mathrm{Tm}_{0.07}\left(\mathrm{WO}_{4}\right)_{2}$ can also be excited at $1064 \mathrm{~nm}$ by a YAG: $\mathrm{Nd}^{3+}$ laser through a photon-avalanche process [45], [46].

Efficient CW laser operation around $2 \mu \mathrm{m}$ was also achieved in $\mathrm{Tm}^{3+}$-doped KGdW [47], where an overall tunability extending from 1790 to $2042 \mathrm{~nm}$ was obtained with maximum output powers of $400 \mathrm{~mW}$ for an absorbed pump power of $1 \mathrm{~W}$. The potential of the novel laser material KLuW: $\mathrm{Tm}^{3+}$ for highly efficient tunable operation in the $2-\mu \mathrm{m}$ spectral range was studied in [48]. The tuning range of 1800-1987 $\mathrm{nm}$ and the high slope efficiency $(69 \%)$ and output power $(4 \mathrm{~W})$ achieved with a diode-pumped laser configuration are promising for various applications.

\section{PlanAR WAVEGUIDE FABRICATION}

In general, waveguide structures exhibit high confinement and excellent mode overlap of pump and laser beams. This feature is of particular advantage for three-level transitions such as the $1-\mu \mathrm{m}$ transition in $\mathrm{Yb}^{3+}$, the $1.5-\mu \mathrm{m}$ transition in $\mathrm{Er}^{3+}$, and the $2-\mu \mathrm{m}$ transitions in $\mathrm{Tm}^{3+}$ and $\mathrm{Ho}^{3+}$. The monoclinic double tungstates possess high refractive indexes, resulting in high refractive index contrasts in structured devices, which makes rare-earth-ion-activated monoclinic double tungstates potentially useful for applications in integrated optics. In the following sections, we focus on our efforts to develop KYW in this direction.

A method of liquid-phase epitaxy (LPE) with vertical substrate dipping has been developed to produce $\mathrm{KYW}: \mathrm{RE}^{3+}(\mathrm{RE}$ : rare-earth ion) thin planar layers. LPE is a well-known technique for producing oxide films for laser applications, in which a crystalline layer can be grown from a molten solution onto an oriented single-crystal substrate [49]. The major advantage of LPE compared to epitaxial techniques from the vapor phase

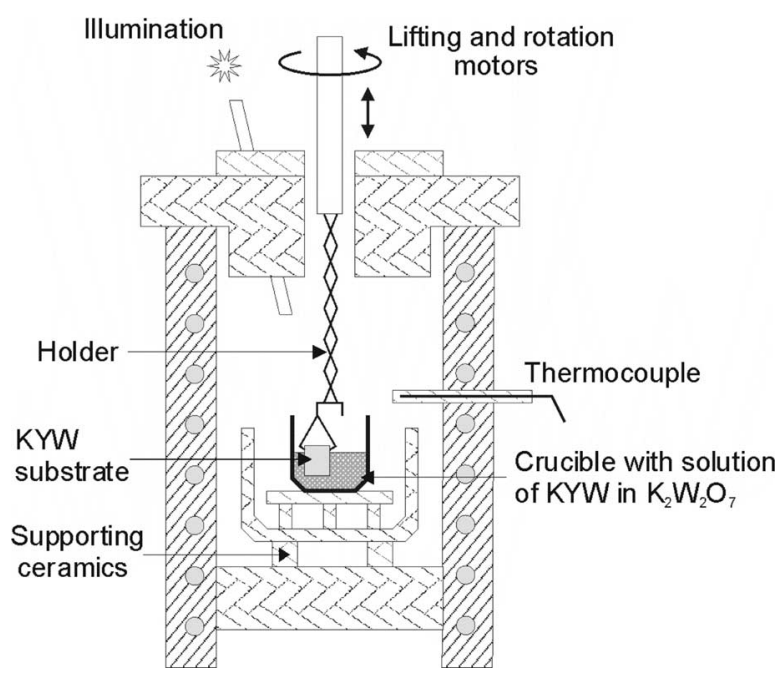

Fig. 1. LPE setup.

is that LPE is a near-thermodynamic equilibrium process, and therefore, high-quality single-crystalline KYW layers are feasible [50].

Fig. 1 shows schematically an experimental LPE setup, based on a nonvacuum resistance-heated furnace with vertical loading. Inside the furnace, there is a crucible filled with a molten solution of KYW in an appropriate solvent. Initially, we tested the low-temperature chloride mixture $\mathrm{NaCl}-\mathrm{KCl}-\mathrm{CsCl}$ as the solvent [51]. However, three-dimensional island nucleation generated insertion defects, which limited the maximum layer thickness to approximately $10 \mu \mathrm{m}$ and led to nonoptimum interface quality. The tungstate solvent $\mathrm{K}_{2} \mathrm{~W}_{2} \mathrm{O}_{7}$, which we employed successfully in the present work, can offer larger thickness and good layer quality. The $\mathrm{K}_{2} \mathrm{~W}_{2} \mathrm{O}_{7}$ solvent contains no impurity ions and exhibits a high solubility for double tungstates [52].

When the liquid solution is being cooled down, at a certain temperature it becomes supersaturated. The substrate, which is a 1-mm-thick undoped KYW crystal with laser-grade polished (lllll $\left.\begin{array}{ll}1 & 0\end{array}\right)$ faces is immersed partially and rotated in the supersaturated solution, and the KYW layer can be grown. Thus, planar KYW layers with thickness $d=5-100 \mu \mathrm{m}$ and a surface area of $\sim 0.5 \mathrm{~cm}^{2}$ can be grown at an average growth rate of $18 \mu \mathrm{m} / \mathrm{h}$ [53]. After the growth, the substrate with layer is withdrawn from the liquid and the whole system is cooled down to room temperature. X-ray diffraction (XRD), optical microscopy, and interferometry confirmed that the layers are single-crystalline and strictly oriented in the $\left[\begin{array}{lll}0 & 1 & 0\end{array}\right]$ crystallographic direction, whereas X-ray fluorescence spectroscopy (XRF) and energydispersive $\mathrm{X}$-ray analysis (EDAX) showed that the layer composition corresponds to that of stoichiometric KYW.

When adding a small amount of $\mathrm{RE}_{2} \mathrm{O}_{3}$ powder to the initial solution, $\mathrm{RE}^{3+}$-doped KYW layers can be grown, where the $\mathrm{RE}^{3+}$ ion substitutes for $\mathrm{Y}^{3+}$. It was shown earlier that the incorporation coefficient of $\mathrm{Yb}^{3+}$ ions into the $\mathrm{KYW}$ matrix during growth from the $\mathrm{K}_{2} \mathrm{~W}_{2} \mathrm{O}_{7}$ solvent is close to unity and the same behavior is expected for other $\mathrm{RE}^{3+}$ ions [54]. Thus, the growth of KYW:RE ${ }^{3+}$ layers with tailored concentration of 


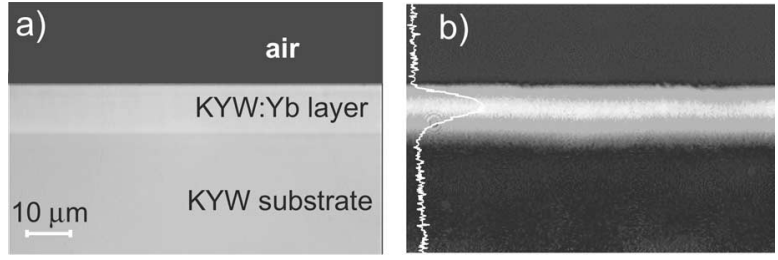

Fig. 2. (a) Optical photograph of the endface of a 1.2 at. $\% \mathrm{Yb}^{3+}$-doped KYW surface layer. (b) Near-field image of the guided pump light and $\mathrm{Yb}^{3+}$ fluorescence outcoupled from the waveguide.

$\mathrm{RE}^{3+}$ ions is possible, knowing the initial ratio of $\mathrm{RE}^{3+} / \mathrm{Y}^{3+}$ in the molten solution. For those $\mathrm{RE}^{3+}$ ions whose ionic radii have a considerable misfit with that of $\mathrm{Y}^{3+}$, there is a certain maximum concentration above which the grown KYW:RE ${ }^{3+}$ layers are cracked because of the accumulated lattice strain. For instance, the maximum concentration of $\mathrm{Yb}^{3+}$ in crack-free $\mathrm{KYW}: \mathrm{Yb}^{3+}$ layers is about 15 at.\% with respect to $\mathrm{Y}^{3+}$ [54]. Typical dopant concentrations used in the present studies were well below the critical concentrations and varied from 1.2 to 2.4 at. $\%$ for $\mathrm{Yb}^{3+}$ and from 0.7 to 1.2 at. $\%$ for $\mathrm{Tm}^{3+}$. Higher dopant concentration can be achieved by using codoping with two different $\mathrm{RE}^{3+}$ ions, e.g., $\mathrm{Lu}^{3+}$ and $\mathrm{Gd}^{3+}$, which have opposite ionic radius misfit with $\mathrm{Y}^{3+}$. Thus, crack-free layers containing 25.3 at. $\% \mathrm{Lu}^{3+}, 13$ at. $\% \mathrm{Gd}^{3+}$, and 1.7 at. $\% \mathrm{Yb}^{3+}$ could be grown [55]. Since $\mathrm{Lu}^{3+}$ and $\mathrm{Yb}^{3+}$ possess similar ionic radii, rather high doping concentrations of the optically active $\mathrm{Yb}^{3+}$ ion can be obtained by replacing $\mathrm{Lu}^{3+}$ with $\mathrm{Yb}^{3+}$.

Since KYW is isostructural to KREW for $\mathrm{RE}=\mathrm{Sm} \ldots \mathrm{Lu}$ $\left(100 \%\right.$ of $\mathrm{Y}^{3+}$ is substituted by $\left.\mathrm{RE}^{3+}\right)$ [2], [56], one can assume that the refractive indexes of KYW:RE ${ }^{3+}$ layers increase linearly with increasing $\mathrm{RE}^{3+}$ concentration. Thus, the refractive index change of a 1.8 at. $\% \mathrm{Yb}^{3+}$-doped layer with respect to the undoped substrate is expected to be $6 \times 10^{-4}$, which was confirmed experimentally by dark $m$-line spectroscopy. The refractive index change can be significantly larger in $\mathrm{Lu}^{3+}$ and $\mathrm{Gd}^{3+}$ codoped KYW: $\mathrm{Yb}^{3+}$ layers, where high concentrations of optically inert $\mathrm{Lu}^{3+}$ and $\mathrm{Gd}^{3+}$ dopants are incorporated to increase the refractive index change up to $7.5 \times 10^{-3}$ [55].

In order to prepare optical waveguides, the surface and both endfaces of the grown KYW: $\mathrm{RE}^{3+}$ layers have to be accurately polished to remove flux residuals and growth steps. As mentioned before, the substrate is only partially immersed in the solution, and its upper part is not covered with the layer. This uncovered part was employed as a reference plane, which allowed us to precisely polish the layer surface parallel to the interface. Polishing with alumina suspensions resulted in a root-meansquare (rms) value of the surface roughness of $2.3 \mathrm{~nm}$. Both endfaces of the waveguides were also polished to laser-grade quality taking precautions to avoid chamfering the layer edge. Fig. 2(a) shows the optical image of the polished endface for a KYW: $\mathrm{Yb}^{3+}$ surface layer. The interface is sharp and straight without any detectable defects.

The layers were tested as active and passive planar waveguides under laser excitation at $981 \mathrm{~nm}$ (InGaAs diode laser), $632.8 \mathrm{~nm}$ (He-Ne laser), or $488 \mathrm{~nm}$ (Ar-ion laser). The pump light was coupled into the active layer along the crystallographic $c$-direction by focusing with a microscope objective. The propagated light was imaged onto the sensor of a CCD camera with another microscope objective. For the $11-\mu \mathrm{m}$-thick waveguide shown in Fig. 2(b), the emitted $\mathrm{Yb}^{3+}$ fluorescence was guided together with the 981-nm pump light in the surface KYW: $\mathrm{Yb}^{3+}$ layer. The vertical intensity profile of the outcoupled light is close to a Gaussian distribution, since only one TE mode at $\lambda=980 \mathrm{~nm}$ can be supported by the $11-\mu \mathrm{m}$-thick planar waveguide in vertical direction.

Propagation losses of the optical waveguides were evaluated by observing the decay of the $\mathrm{Yb}^{3+}$-fluorescence intensity emitted perpendicular to the waveguide plane as well as by evaluating the laser performance and were found to be only $0.1-0.2 \mathrm{~dB} / \mathrm{cm}$ at $981 \mathrm{~nm}$. This confirms the high structural quality of the LPE-grown KYW: $\mathrm{RE}^{3+}$ planar layers, which can be used as the starting point for the fabrication of complex buried or channel-waveguide structures.

\section{WAVEGUIDE LASER PERFORMANCE}

For our initial waveguide laser investigations, typically 6-mm-long planar waveguide samples consisting of an undoped KYW substrate and an LPE-grown, rare-earth-ion-doped KYW layer, in some cases overgrown by an undoped KYW film, were prepared. All samples were endface polished, and the surface waveguides were additionally surface polished. The waveguide endfaces remained uncoated.

The waveguide was mounted on a copper plate without active cooling and positioned between the two folding mirrors of an open Z- or X-type resonator, such that the resonator waist was located at both endfaces of the waveguide, and negligible diffraction losses occurred for the resonator mode at the waveguide endfaces. The waveguide was positioned at Brewster angle to minimize the loss in the laser cavity and to determine the laser polarization. The waveguide orientation corresponded to propagation approximately along the $N_{\mathrm{g}}$ principal optical axis and polarization parallel to the $N_{\mathrm{m}}$ axis. The pump polarization was parallel to the $N_{\mathrm{m}}$ axis. Due to the chosen thickness between 15 and $40 \mu \mathrm{m}$, each waveguide supported propagation of a relatively high number of transverse modes in its guiding direction. The resonator was adjusted to match the resonator waist size with the waist of the transverse fundamental mode of the waveguide, and the observed far-field laser intensity distributions indicate that the laser output was close to the diffraction limit in almost all samples and at all output powers.

In the following sections, the waveguide laser operation of $\mathrm{Yb}^{3+}$-doped samples at the $1-\mu \mathrm{m}$ transition ${ }^{2} \mathrm{~F}_{5 / 2} \rightarrow{ }^{2} \mathrm{~F}_{7 / 2}$ [53] and $\mathrm{Tm}^{3+}$-doped samples at the $2-\mu \mathrm{m}$ transition ${ }^{3} \mathrm{~F}_{4} \rightarrow{ }^{3} \mathrm{H}_{6}$ [57] will be reviewed. These three-level laser transitions profit from the high pump confinement in the active layer, as reabsorption of oscillating laser light can be greatly reduced.

\section{A. $\mathrm{Yb}^{3+}$-Doped $\mathrm{KY}\left(\mathrm{WO}_{4}\right)_{2}$ Planar Waveguide Laser}

One buried $(d=17 \mu \mathrm{m})$ and two surface $(d=17$ and $35 \mu \mathrm{m})$ $\mathrm{KYW}: \mathrm{Yb}^{3+}$ waveguides were selected for laser experiments. An astigmatically compensated Z-shaped cavity was chosen (inset 


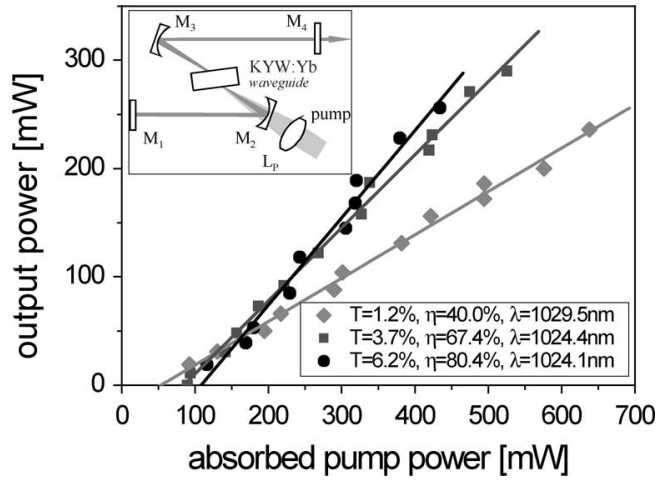

Fig. 3. Laser output power versus absorbed pump power of $17-\mu \mathrm{m}$-thick surface $\mathrm{KYW}: \mathrm{Yb}^{3+}$ planar waveguides for different transmissions of the output coupler. (Inset) Setup of the $\mathrm{Z}$-shaped laser cavity. $\mathrm{L}_{p}$ : focusing pump lens; $\mathrm{M}_{1}$, $\mathrm{M}_{2}, \mathrm{M}_{3}$ : high reflecting mirrors $\left(\mathrm{M}_{2}, \mathrm{M}_{3}: \mathrm{ROC}=-10 \mathrm{~cm}\right), \mathrm{M}_{4}$ : plane output coupler.

in Fig. 3). The KYW: $\mathrm{Yb}^{3+}$ layers were pumped in a single pass by a $\mathrm{CW} \mathrm{Al}_{2} \mathrm{O}_{3}: \mathrm{Ti}^{3+}$ laser operating at $980.5 \mathrm{~nm}$.

Independent of the output coupler transmission $T_{\mathrm{OC}}$, which was chosen between $1.2 \%$ and $6.2 \%$, stable $\mathrm{CW}$ oscillation near $\lambda=1025 \mathrm{~nm}$ was achieved for all waveguides investigated. Because of the reduced reabsorption of oscillating laser light, the spectral laser emission corresponded to the maximum of the gain curve. The output was $95 \%$ linearly polarized. The best laser performance was achieved with the $17-\mu \mathrm{m}$-thick surface waveguide doped with 1.2 at. $\% \mathrm{Yb}^{3+}$. With $T_{\mathrm{OC}}=3.7 \%$, the laser threshold was only $80 \mathrm{~mW}$ of absorbed pump power and the maximum output power amounted to $290 \mathrm{~mW}$, resulting in a slope efficiency versus absorbed pump power of $\eta=67.4 \%$. A maximum slope efficiency of $80.4 \%$ was obtained for $T_{\mathrm{OC}}=6.2 \%$, corresponding to a pump efficiency of $58.9 \%$ (Fig. 3). Although a buried waveguide should, in principle, exhibit lower propagation losses, the laser performance of the buried 2.4 at. $\%$ $\mathrm{KYW}: \mathrm{Yb}^{3+}$ waveguide was slightly inferior, presumably as a result of the higher doping concentration, which led to higher reabsorption losses. When applying a chopper with a duty cycle of $10 \%$, the output power decreased 10 times. Hence, it can be concluded that no thermal problems occur up to the maximum applied pump power of $2 \mathrm{~W}$ despite the absence of cooling. Cavity round-trip losses of $1.8-2.1 \%$ were derived from the slope efficiencies obtained in 17- $\mu \mathrm{m}$-thick surface and buried planar waveguides [58]. Attributing this loss completely to waveguide propagation losses leads to an upper limit of $\sim 0.08 \mathrm{~dB} / \mathrm{cm}$ for the waveguide losses.

The absorption characteristics of the buried KYW: $\mathrm{Yb}^{3+}$ waveguides are shown in Fig. 4. The measured small-signal absorption below laser threshold of about 50\% confirms roughly the calculated value by taking into account the overlap of the pump mode with the waveguide dimensions. Under lasing conditions with an output coupler transmission of $1 \%$, the actual fraction of absorbed pump power remained nearly constant independent of the power absorbed, while in the absence of lasing it dropped from $50 \%$ to $18 \%$. This absorption behavior indicates that the saturation intensity at the pump wavelength was increased in the lasing state and the bleaching effect was sup-

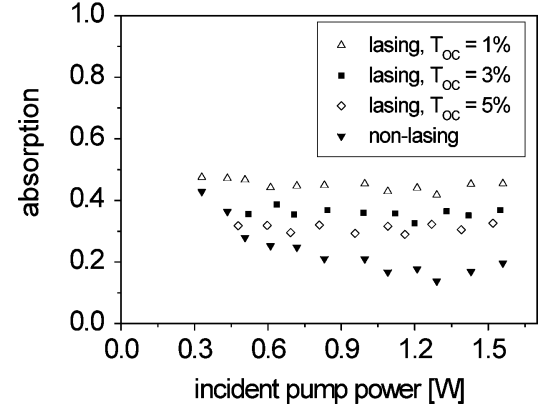

Fig. 4. Measured single-pass absorption versus incident pump power of the $\mathrm{KYW}: \mathrm{Yb}^{3+}$ buried waveguide.

pressed. By increasing the output coupling, the bleaching effect became visible. Similar dependencies for the absorption were observed for all $\mathrm{KYW}: \mathrm{Yb}^{3+}$ waveguides investigated.

The waveguiding effect of the layers was verified in a simple linear laser cavity, in which we compared the laser performance of bulk and waveguide samples versus the resonator length $L$. For the chosen, nearly hemispherical resonator with a fixed radius of curvature (ROC) of the output coupler, the losses are expected to increase rapidly when $L>$ ROC, because the resonator becomes unstable. While the bulk laser operated only for resonator lengths shorter than this critical mirror separation, laser operation of the waveguide sample could be achieved for resonator lengths that exceeded the critical mirror separation almost by the length of the waveguide sample. This shift indicates that the waist of the resonator mode moves from the plane mirror to the opposite waveguide endface without substantially changing the resonator losses, i.e., the laser resonator remains stable even for $L>$ ROC [59]. This is a clear indication of the guiding behavior of the active layer.

\section{B. $\mathrm{Tm}^{3+}$-Doped $\mathrm{KY}\left(\mathrm{WO}_{4}\right)_{2}$ Planar Waveguide Laser}

Two KYW: $\mathrm{Tm}^{3+}$ planar waveguides consisting of 39- and $35-\mu \mathrm{m}$-thick active layers were selected for initial laser experiments, the thicker sample being 1.2 at.\% and the thinner 1.0 at.\% $\mathrm{Tm}^{3+}$ doped.

The samples were placed in an astigmatically compensated X-type cavity with a total length of $85 \mathrm{~cm}$, between the two $10-\mathrm{cm}$ folding mirrors. Three mirrors were highly reflecting $(R>99.9 \%$ ) from 1800 to $2075 \mathrm{~nm}$ and antireflection-coated on the rear side for high transmission from 780 to $1020 \mathrm{~nm}$, and one mirror was used as output coupler.

The KYW: $\mathrm{Tm}^{3+}$ layer was pumped in a single pass by a tunable $\mathrm{CW} \mathrm{Al}_{2} \mathrm{O}_{3}: \mathrm{Ti}^{3+}$ laser delivering a nearly diffraction limited output beam with power of $3 \mathrm{~W}$ near $800 \mathrm{~nm}$ and $0.2-\mathrm{nm}$ linewidth when pumped with an all-lines Ar-ion laser. A 70-mm focusing lens was used to couple the pump beam through one of the folding mirrors into the planar waveguide. At the position of the waveguide endface, the pump spot had a Gaussian waist of $37 \mu \mathrm{m}$.

CW laser operation was obtained for output coupler transmissions between $1 \%$ and $5 \%$. A photograph of the $35-\mu \mathrm{m}$-thick $\mathrm{KYW}: \mathrm{Tm}^{3+}$ waveguide in the lasing state, placed on a copper 


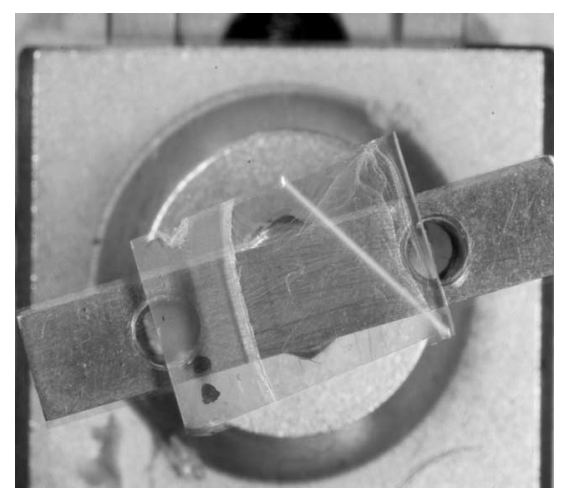

Fig. 5. Photograph of the KYW: $\mathrm{Tm}^{3+}$ waveguide placed on a Cu plate in the lasing state. The fluorescence crossing the waveguide under Brewster angle has a reddish color and indicates the pump channel.
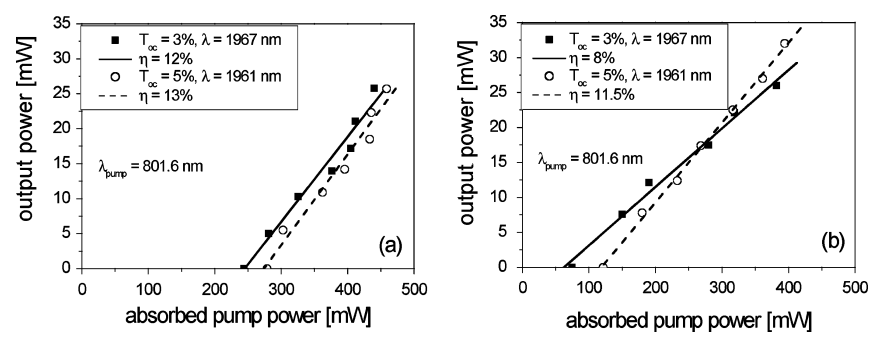

Fig. 6. CW output power versus absorbed pump power of the KYW: $\mathrm{Tm}^{3+}$ planar waveguide lasers for two output couplers. (a) $39 \mu \mathrm{m}$ thick, 1.2 at.\% $\mathrm{Tm}^{3+}$-doped active layer. (b) $35 \mu \mathrm{m}$ thick, 1.0 at. $\% \mathrm{Tm}^{3+}$-doped active layer ( $T_{\mathrm{OC}}$ : output coupler transmission, $\eta$ : slope fficiency).

plate, is shown in Fig. 5. The reddish fluorescence, indicating the pump channel, originates from upconversion fluorescence from the ${ }^{1} \mathrm{G}_{4}$ and possibly ${ }^{1} \mathrm{D}_{2}$ levels, and the visible dislocations of the sample stem from the bottom side of the substrate that is not polished.

The laser performance of the two waveguides is presented in Fig. 6. Depending on the output coupler transmission, the laser emission was between 1960 and $1970 \mathrm{~nm}$. Best laser performance was achieved when pumping into the absorption peak at $801.6 \mathrm{~nm}$. The laser threshold of the $39-\mu \mathrm{m}$-thick layer was reached at an absorbed pump power of $244 \mathrm{~mW}$. The output power amounted to $26 \mathrm{~mW}$ for both, $T_{\mathrm{OC}}=3 \%$ and $T_{\mathrm{OC}}=5 \%$. The slope efficiency $\eta$ was maximum for $T_{\mathrm{OC}}=5 \%$ and amounted to $13 \%$ with respect to the absorbed pump power. The lowest laser threshold of $75 \mathrm{~mW}$ of absorbed pump power was achieved with the $35-\mu \mathrm{m}$-thick, 1.0 at. $\% \mathrm{Tm}^{3+}$-doped waveguide and $T_{\mathrm{OC}}=3 \%$. The maximum output power was measured to be $32 \mathrm{~mW}$ with $T_{\mathrm{OC}}=5 \%$, resulting in a slope efficiency versus absorbed pump power of $\eta=11.5 \%$. The three times lower laser threshold of the 1.0 at. $\% \mathrm{KYW}: \mathrm{Tm}^{3+}$ waveguide is presumably a result of the lower doping concentration, which led to reduced reabsorption losses. The slope efficiencies of the two waveguides are rather similar, slightly higher for the 1.2 at.\% Tm sample. The maximum optical-to-optical conversion efficiency achieved with the $35-\mu$ m-thick sample is only about $8 \%$, which is mainly due to the two times larger pump spot-size compared to the active layer thickness.

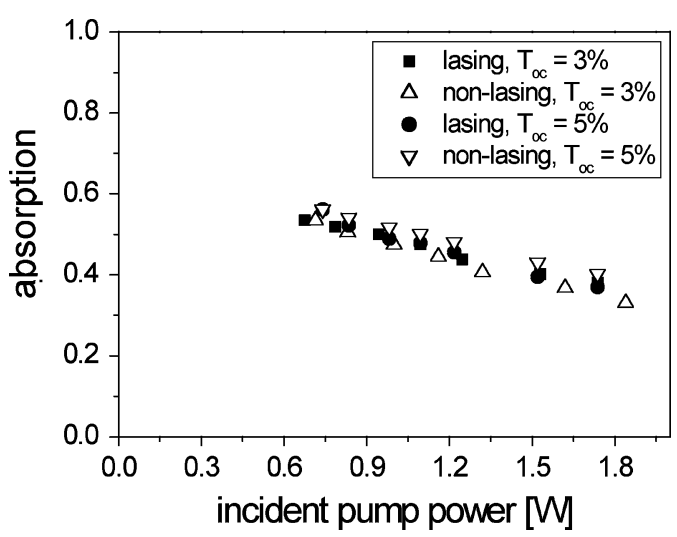

Fig. 7. Measured single-pass absorption versus incident pump power of the $39-\mu$ m-thick, 1.2 at. $\% \mathrm{Tm}^{3+}$-doped $\mathrm{KYW}$ waveguide.

The absorption behavior of the 39- $\mu$ m-thick, 1.2 at. $\% \mathrm{Tm}^{3+}$. doped waveguide is shown in Fig. 7. The calculated small-signal pump absorption yields a value of about $90 \%$. The measured absorption of $60 \%$ confirms roughly the overlap integral of the pump mode and the mode size inside the planar waveguide. The fraction of absorbed pump power dropped from $60 \%$ at low pump power down to about $30 \%$ at the maximum applied pump power. We could not detect a noticeable difference between the fraction of absorbed pump power in the lasing and nonlasing states, which is similar to the behavior obtained in $\mathrm{Tm}^{3+}$-doped double tungstate bulk lasers [48]. This behavior indicates that the pump saturation intensity is not strongly increased in the lasing state and the bleaching effect remains, as can be expected from the low intracavity power. The measured difference in absorption between the $39-\mu$ m-thick, 1.2 at. $\% \mathrm{Tm}^{3+}$-doped and the $35-\mu \mathrm{m}$-thick, 1 at. $\% \mathrm{Tm}^{3+}$-doped waveguides is only $3 \%$. With respect to the different doping levels, a higher difference is expected, which underlines the present absorption bleaching effect. Similar absorption behavior was observed for all samples investigated.

Thinner waveguides with a KYW: $\mathrm{Tm}^{3+}$ layer thickness of 20 and $18 \mu \mathrm{m}$ were also examined. Both were demonstrated to lase, but the maximum output power was limited to 8.5 and $6 \mathrm{~mW}$, respectively. Their performance was slightly inferior to that of the thicker waveguides, although the $\mathrm{Tm}^{3+}$-doping concentration of 1.2 and 1.0 at. $\% \mathrm{Tm}^{3+}$ was comparable. We attribute the worse performance to a less good matching of the waveguide thickness to the pump mode profile and a higher diffraction loss at the waveguide/air interface.

In general, the laser performance with respect to slope efficiency and output power was inferior in comparison to the excellent results achieved with the $\mathrm{KYW}: \mathrm{Yb}^{3+}$ waveguide lasers (Section IV-A). Comparison of the visible fluorescence spectrum of one KYW:Tm ${ }^{3+}$ planar waveguide to that of a $\mathrm{KLuW}: \mathrm{Tm}^{3+}$ bulk crystal that had proved its excellent suitability as laser crystal in the $2-\mu \mathrm{m}$ spectral range [48] did not reveal any additional loss channels, like energy transfer to $\mathrm{Er}^{3+}$ impurities, in the $\mathrm{Tm}^{3+}$-doped waveguide within this spectral window. 


\section{TOWARD ON-CHIP INTEGRATED OPTICAL STRUCTURES}

The first step in the direction of optical integration on a chip is the fabrication of channel waveguides. Recently, in collaboration with colleagues from the University of Southampton, U.K., the University of Lyon, France, and the Politecnico di Milano, Italy, we investigated a number of methods for surface structuring and/or two- and three-dimensional refractive index modification in $\mathrm{Al}_{2} \mathrm{O}_{3}$ and $\mathrm{Al}_{2} \mathrm{O}_{3}: \mathrm{Ti}^{3+}$ [60], such as reactive ion etching [61] and Ar-ion milling [62], ion beam implantation [63], and femtosecond laser writing [64]. Especially, the etched but also the ion-implanted channel waveguides demonstrated their suitability for surface [65] and buried [66] channel waveguide lasing.

\section{A. Channel Waveguide Fabrication}

In principle, all these methods are also suitable for the fabrication of channel waveguides in monoclinic double tungstates; however, the employed recipes need to be adjusted specifically to these materials.

Implantation of light ions such as $\mathrm{H}^{+}$and $\mathrm{He}^{+}$with energies in the $\mathrm{MeV}$ range leads to a deposition of most of the ions' kinetic energy in a small area a few micrometers below the surface. The induced structural changes result in a refractive index modification that, dependent on the nature of the material, can be positive or negative. Like in $\mathrm{Al}_{2} \mathrm{O}_{3}$, our investigations showed that implantation of $\mathrm{H}^{+}$or $\mathrm{He}^{+}$into KYW resulted in negative refractive index changes. Therefore, we employed the same strategy of implanting the surrounding areas [63] in order to form negative refractive index barriers around the waveguide channel. However, while in $\mathrm{Al}_{2} \mathrm{O}_{3}$, implantation of $\mathrm{H}^{+}$ produced much lower damage in the waveguide area than did the implantation of $\mathrm{He}^{+}$, in $\mathrm{KYW}$, the damage produced by $\mathrm{H}^{+}$ions on their way through the intended waveguide area led to increased propagation losses and practically excluded this method as a suitable approach for channel waveguide fabrication [67]. On the other hand, implantation of $\mathrm{He}^{+}$ions led to good results [68]. We implanted $\mathrm{He}^{+}$ions at various doses normal to the optically polished surface of bulk $\left(\begin{array}{lll}0 & 1 & 0\end{array}\right)$ oriented KYW single crystals by the use of a Van de Graaf accelerator operating at beam currents in the range of $0.6-0.8 \mathrm{~mA} / \mathrm{cm}^{2}$ at a controlled temperature of $20^{\circ} \mathrm{C}$. An ion energy of $1.5 \mathrm{MeV}$ led to an implantation peak about $3.5 \mu \mathrm{m}$ below the surface. Refractive index changes depended on optical axis and were in the range of $-1 \times 10^{-2}$ for a dose of $2 \times 10^{16}$ ions $/ \mathrm{cm}^{2}$. With different implantation schemes, planar and channel waveguides were fabricated in $\mathrm{KYW}$ and $\mathrm{KYW}: \mathrm{Yb}^{3+}$ bulk samples, and channel waveguides were fabricated in LPE-grown $\mathrm{KYW}: \mathrm{Yb}^{3+}$ epitaxial planar waveguides with $\mathrm{He}^{+}$-implanted side barriers [69]. In the latter, the propagation losses were measured to be $\sim 0.5 \mathrm{~dB} / \mathrm{cm}$.

Femtosecond laser writing has proved to be a versatile method for waveguide writing in glasses. In hard crystalline materials, often a visible damage and negative refractive index change occurs in the irradiated area. Our investigations show that this is also the case in $\mathrm{KYW}$ and $\mathrm{KYW}: \mathrm{Yb}^{3+}$. Therefore, waveguiding can be achieved only in the region between two such irradi-
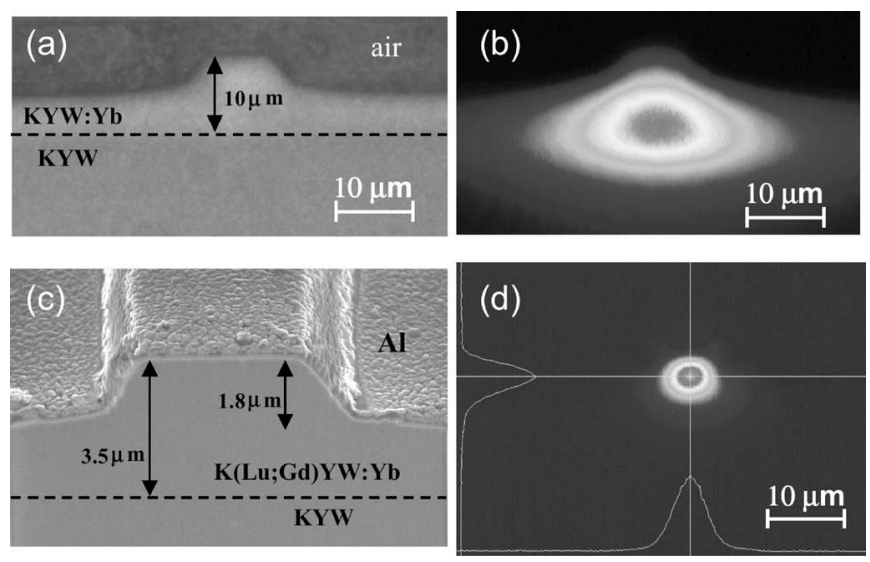

Fig. 8. Endface cross section. (a) With an optical microscope of a KYW:Yb ${ }^{3+}$ layer with low refractive index contrast. (c) With a scanning electron microscope of a Lu, Gd codoped KYW: $\mathrm{Yb}^{3+}$ layer with high refractive index contrast. Mode intensity profiles. (b) KYW: $\mathrm{Yb}^{3+}$. (d) Lu, Gd codoped KYW:Yb ${ }^{3+}$.

ated areas or at the tips of a cigar-shaped damaged area where a compressive-lattice-strain-induced refractive index enhancement can be exploited [64]. Currently, these ways to fabricate buried channel waveguides lead to rather uncontrolled guiding regions and relatively high losses. We employed an $\mathrm{Al}_{2} \mathrm{O}_{3}: \mathrm{Ti}^{3+}$ regenerative amplifier at $800 \mathrm{~nm}$, with a repetition rate of $100 \mathrm{kHz}$ and a pulse duration of $200 \mathrm{fs}$ in the $1-20 \mu \mathrm{J}$ singlepulse energy regime. The beam was focused $200 \mu$ m underneath the polished surface plane by the use of either $25 \times$ or $40 \times$ optical microscope objectives with 0.5 or 0.65 numerical aperture, respectively. In the case of KYW, we demonstrated buried channel waveguides with propagation losses of at least $2-2.5 \mathrm{~dB} / \mathrm{cm}$ at 670 or $980 \mathrm{~nm}$ [70].

Surface channel waveguides were fabricated by reactive ion etching. While $\mathrm{Al}_{2} \mathrm{O}_{3}$ can be etched with chlorine or bromine chemistry [61] because of the high volatility of $\mathrm{AlCl}_{3}$ and $\mathrm{AlBr}_{3}$, we found that for etching KYW and $\mathrm{KYW}: \mathrm{Yb}^{3+}$, fluorine chemistry is better suited [69]. We employed photoresist, metal, and semiconductor masks that were deposited onto the KYW substrates using standard UV-photolithography methods. The best results were obtained with polysilicon masks. The etch rate in KYW was 35-40 nm/min and ribs as deep as $6 \mu \mathrm{m}$ were obtained in KYW: $\mathrm{Yb}^{3+}$ films of $10-\mu \mathrm{m}$ thickness (Fig. 8(a) and (b)). Relatively high propagation losses of $5.5 \mathrm{~dB} / \mathrm{cm}$ at $670 \mathrm{~nm}$ and $3.2 \mathrm{~dB} / \mathrm{cm}$ at $981 \mathrm{~nm}$ were measured with different techniques.

\section{B. Integrated Structures}

As mentioned in Section III, the refractive index of $\mathrm{KYW}: \mathrm{RE}^{3+}$ can be approximated to be proportional to the $\mathrm{RE}^{3+}$ concentration. Therefore, the refractive index contrast of $\mathrm{KYW}: \mathrm{Yb}^{3+}$ layers with respect to the KYW bulk substrates is limited by the level of $\mathrm{Yb}^{3+}$ doping, which is defined by the optical application. For waveguide laser applications using a standard end-pumping scheme, the high absorption cross section of $\mathrm{Yb}^{3+}$ ions in KYW at $981 \mathrm{~nm}$ results in a very short pump-absorption length; a pure $\mathrm{KYbW}$ crystal has an absorption 
TABLE I

Lattice Constants of Monoclinic Potassium Double TungState Compounds at RoOm Temperature

\begin{tabular}{|c|c|c|c|c|c|}
\hline Compound & $\mathrm{a}(\mathrm{nm})$ & $\mathrm{b}(\mathrm{nm})$ & $\mathrm{c}(\mathrm{nm})$ & $\beta(\circ)$ & Ref. \\
\hline $\mathrm{KYW}$ & 1.06313 & 1.03452 & 0.75547 & 130.752 & {$[71]$} \\
\hline $\mathrm{KGdW}$ & 1.0652 & 1.0374 & 0.7582 & 130.80 & {$[71]$} \\
\hline $\mathrm{KYbW}$ & 1.0590 & 1.0290 & 0.7478 & 130.70 & {$[56]$} \\
\hline $\mathrm{KLuW}$ & 1.0576 & 1.0214 & 0.7487 & 130.68 & {$[72]$} \\
\hline
\end{tabular}

length of $13 \mu \mathrm{m}$. Therefore, the $\mathrm{Yb}^{3+}$-ion concentration has to be adjusted carefully in order to minimize reabsorption losses. A total of 1.7 at. $\% \mathrm{Yb}^{3+}$ concentration is well adapted for 6-mm-long samples [53]. The corresponding refractive index difference with respect to the KYW substrate is as low as $\Delta n=6 \times 10^{-4}$.

The realization of single-mode waveguide structures with improved light confinement requires higher refractive index contrast, while keeping the $\mathrm{Yb}^{3+}$-ion doping level fixed. To achieve this goal, we employed codoping with optically inert $\mathrm{Gd}^{3+}$ and $\mathrm{Lu}^{3+}$ ions. The refractive indexes of $\mathrm{KLuW}$ and KGdW are, approximately, $2 \times 10^{-2}$ and $1 \times 10^{-2}$ higher, respectively, than those of KYW, whereas the lattice parameters of KLuW and KGdW go into opposite directions compared to those of KYW (Table I). Thus, a large refractive index increase, and simultaneously, a match of the lattice parameters of the layer with the substrate parameters can be engineered. In addition, since KLuW and KYbW possess very similar lattice constants (Table I), $\mathrm{Lu}^{3+}$ ions can be gradually replaced by $\mathrm{Yb}^{3+}$ ions without adversely affecting the lattice match between layer and substrate, thereby providing a rather large flexibility concerning the dopant concentration of the optically active $\mathrm{Yb}^{3+}$ ion.

Our optimized, actively doped layers were composed of $\mathrm{KLu}_{0.253} \mathrm{Gd}_{0.13} \mathrm{Yb}_{0.017} \mathrm{Y}_{0.6}\left(\mathrm{WO}_{4}\right)_{2}$ [55]. A refractive index difference of $7.5 \times 10^{-3}$ with respect to the undoped substrate was measured by dark m-lines spectroscopy. Planar layers on KYW substrates with thicknesses as small as $1.5 \mu \mathrm{m}$ can be used for propagating the 1020-nm fluorescence signal of $\mathrm{Yb}^{3+}$ ions in the fundamental mode. Channel waveguide structures were fabricated from such layers using reactive ion etching, as described in Section V-A. Ridge channel waveguides with widths from 3 to $9 \mu \mathrm{m}$ were patterned in a 3.5- $\mu$ m-thick $\mathrm{KLu}_{0.253} \mathrm{Gd}_{0.13} \mathrm{Yb}_{0.017} \mathrm{Y}_{0.6}\left(\mathrm{WO}_{4}\right)_{2}$ layer with an etching height of $1.8 \mu \mathrm{m}$ (Fig. 8(c)) and well-confined guided fundamental-mode fluorescence was observed when pumping at $980 \mathrm{~nm}$ (Fig. 8(d)). The lateral and vertical mode dimensions were $5.8 \mu$ nd $3.9 \mu \mathrm{m}$, respectively, and were well matched to those of standard single-mode fibers. The waveguide propagation losses at $670 \mathrm{~nm}$ were $4.8 \mathrm{~dB} / \mathrm{cm}$. Since the losses are mainly caused by Rayleigh scattering, i.e., scale with $\lambda^{-4}$, the propagation losses at the fluorescence wavelength are expected to be below $1 \mathrm{~dB} / \mathrm{cm}$ for all single-mode ribs.

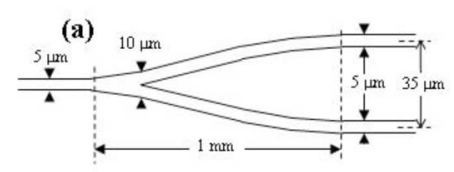

(c)
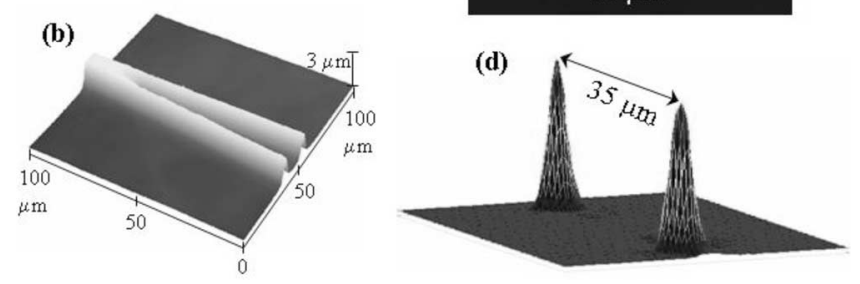

Fig. 9. (a) Schematic layout of the Y splitter. (b) Topology of the splitting part of the junction measured by AFM. Fluorescence intensity distribution $(\lambda=1020 \mathrm{~nm})$ at the exit of the Y splitter when 980-nm pump light is fiber end-coupled. (c) Two-dimensional view. (d) Three-dimensional view.

In these $\mathrm{Lu}^{3+}, \mathrm{Gd}^{3+}$ codoped $\mathrm{KYW}: \mathrm{Yb}^{3+}$ epilayers, we have designed Y-splitters [55]. The dimensions presented in Fig. 9(a) have been chosen to minimize the radiation losses both in the linear taper and the splitting parts of the junction [73]. The input and two output waveguides are characterized by a $5-\mu \mathrm{m}$ width and a single-mode behaviour for $\lambda=1020 \mathrm{~nm}$. Fig. 9(b) shows an atomic force microscope image of the junction. Fig. 9(c) and (d) depicts the symmetric fluorescence intensity distribution at the output endface of the sample when 980-nm pump light is coupled into the waveguide splitter. The splitting ratio is close to $1: 1$ and does not depend on the coupling conditions. The additional splitting losses were $1.4 \mathrm{~dB}$ at $820 \mathrm{~nm}$.

These thin, high-refractive-index-contrast channel waveguides also offer great potential for the realization of nanostructured waveguides, such as Bragg grating filters and even distributed Bragg reflection or distributed-feedback microlasers. Focused ion beam etching was employed for the realization of Bragg filters on $\mathrm{KYW}: \mathrm{Lu}^{3+}, \mathrm{Gd}^{3+}, \mathrm{Yb}^{3+}$ channel waveguides. A 20-nm-thick aluminum layer was chosen to reduce charging effects. The dimensions and the grating shape were fixed by numerical simulations to obtain Bragg filters at $\lambda \approx 1020 \mathrm{~nm}$. Gratings with a periodicity of $250 \mathrm{~nm}$ and high aspect ratio were milled on the KYW: $\mathrm{Lu}^{3+}, \mathrm{Gd}^{3+}, \mathrm{Yb}^{3+}$ ribs (see Fig. 10) [74]. Current work concentrates on the optical characterization and optimization of these first Bragg filters produced in a double tungstate material. 

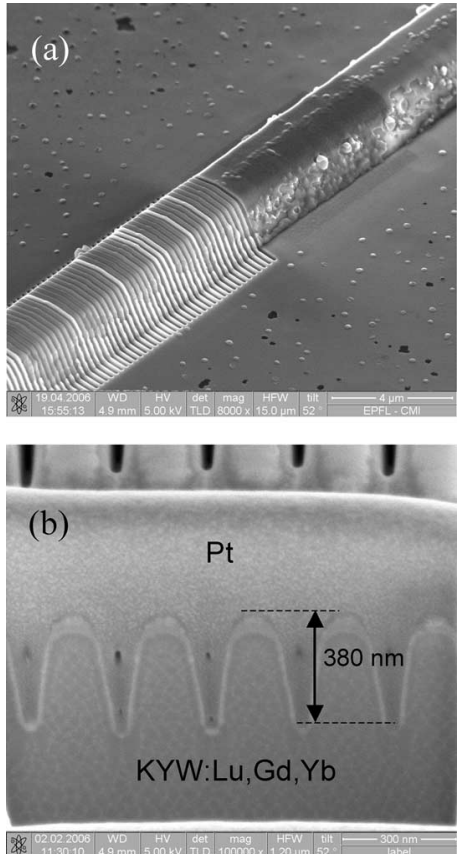

Fig. 10. Scanning electron microscope pictures of a Bragg grating in a KYW:Gd, Lu, Yb channel waveguide. (a) Top view. (b) Cross section.

\section{CONCLUSION}

In this paper, we have reviewed the results on solid-state lasers in rare-earth-ion-doped double tungstates $\mathrm{KYW}, \mathrm{KGdW}$, and $\mathrm{KLuW}$, with an emphasis on the recent work performed in our research groups on KYW waveguide structures and lasers. In future, we will focus on higher output powers and efficiencies, and especially, on establishing on-chip integrated laser structures for applications in high-output-power integrated optics.

\section{ACKNOWLEDGMENT}

The authors thank their colleagues D. Ehrentraut, L. Laversenne, V. Apostolopoulos, F. Zäh, C. Schnider, I. Utke, M. Jenke, P. Hoffmann, R. P. Salathé, C. Hibert, M. Pavius, and B. Deveaud-Pledran from the Swiss Federal Institute of Technology, Lausanne, Switzerland, and X. Mateos and G. Steinmeyer from the Max-Born-Institute, Berlin, Germany, as well as the research group of F. Díaz, Tarragona, Spain, P. Moretti, Lyon, France, S. García-Revilla and R. Valiente, Santander, Spain, the research group of H. U. Güdel, Bern, Switzerland, M.-P. Bernal, Besançon, France, N. V. Kuleshov, Minsk, Belarus, and L. Kuandykov, St. Petersburg, Russia, for their contributions to the experiments and helpful discussions.

\section{REFERENCES}

[1] S. V. Borisov and R. F. Klevtsova, "Crystal structure of $\mathrm{KY}\left(\mathrm{WO}_{4}\right)_{2}$," Sov. Phys. Crystallogr., vol. 13, pp. 420-421, 1968, (Transl.: Kristallografiya, vol. 13, pp. 517-519, 1968).

[2] P. V. Klevtsov and L. P. Kozeeva, "Synthesis and X-ray and thermal studies of potassium rare-earth tungstates, $\mathrm{KLn}\left(\mathrm{WO}_{4}\right)_{2}, \mathrm{Ln}=$ rare-earth element," Sov. Phys. Doklady, vol. 14, pp. 185-187, 1969, (Transl.: Doklady Akademii Nauk SSSR, vol. 185, pp. 571-574, 1969).

[3] C. Pujol, M. Aguiló, F. Díaz, and C. Zaldo, "Growth and characterisation of monoclinic $\mathrm{KGd1-xREx}\left(\mathrm{WO}_{4}\right)_{2}$ single crystals," Opt. Mater., vol. 13, pp. 33-40, 1999.
[4] G. Métrat, M. Boudeulle, N. Muhlstein, A. Brenier, and G. Boulon, "Nucleation, morphology and spectroscopic properties of $\mathrm{Yb}^{3+}$-doped $\mathrm{KY}\left(\mathrm{WO}_{4}\right)_{2}$ crystals grown by the top nucleated floating crystal method," J. Cryst. Growth, vol. 197, pp. 883-888, 1999.

[5] A. A. Kaminskii, K. Ueda, H. E. Eichler, J. Findeisen, S. N. Bagaev, F. A. Kuznetsov, A. A. Pavlyuk, G. Boulon, and F. Bourgeois, "Monoclinic tungstates $\mathrm{KDy}\left(\mathrm{WO}_{4}\right)_{2}$ and $\mathrm{KLu}\left(\mathrm{WO}_{4}\right)_{2}$-new $\chi^{(3)}$-active crystals for laser Raman shifters," Jpn. J. Appl. Phys., vol. 37, pp. L923-L926, 1998.

[6] I. V. Mochalov, "Laser and nonlinear properties of the potassium gadolinium tungstate laser crystal $\mathrm{KGd}\left(\mathrm{WO}_{4}\right)_{2}: \mathrm{Nd}^{3+}{ }^{3+}(\mathrm{KGW}: \mathrm{Nd})$," Opt. Eng., vol. 36, pp. 1660-1669, 1997.

[7] A. A. Lagatsky, N. V. Kuleshov, and V. P. Mikhailov, "Diode-pumped CW lasing of Yb:KYW and Yb:KGW," Opt. Commun., vol. 165, pp. 71-75, 1999.

[8] N. V. Kuleshov, A. A. Lagatsky, V. G. Shcherbitsky, V. P. Mikhailov, E. Heumann, T. Jensen, A. Diening, and G. Huber, "CW laser performance of $\mathrm{Yb}$ and Er, $\mathrm{Yb}$ doped tungstates," Appl. Phys. B, vol. 64, pp. 409-413, 1997.

[9] W. F. Krupke, "Ytterbium solid-state lasers-The first decade," IEEE $J$ Sel. Topics Quantum Electron., vol. 6, no. 6, pp. 1287-1296, Nov./Dec. 2000.

[10] P. Lacovara, H. K. Choi, C. A. Wang, R. L. Aggarwal, and T. Y. Fan, "Room-temperature diode-pumped Yb:YAG laser," Opt. Lett., vol. 16, pp. 1089-1091, 1991.

[11] K. Petermann, D. Fagundes-Peters, J. Johannsen, M. Mond, V. Peters, J. J. Romero, S. Kutovoi, J. Speiser, and A. Giesen, "Highly Yb-doped oxides for thin-disc lasers," J. Cryst. Growth, vol. 275, pp. 135-140, 2005.

[12] V. Petrov, X. Mateos, S. Rivier, O. Silverstre, M. Aguilo, R. Solé, M. C. Pujol, J. Liu, U. Griebner, and F. Díaz, "Novel ytterbium and thulium lasers based on the monoclinic $\mathrm{KLu}\left(\mathrm{WO}_{4}\right)_{2}$ crystalline host," Proc. SPIE, vol. 6604, pp. 66040V-1-66040V-14, 2007.

[13] A. A. Demidovich, A. N. Kuzmin, G. I. Ryabtsev, M. B. Danailov, W. Strek, and A. N. Titov, "Influence of Yb concentration on Yb:KYW laser properties," J. Alloys Compound, vol. 300/301, pp. 238-241, 2000.

[14] N. V. Kuleshov, A. A. Lagatsky, A. V. Podlipensky, V. P. Mikhailov, and G. Huber, "Pulsed laser operation of Yb-doped $\mathrm{KY}\left(\mathrm{WO}_{4}\right)_{2}$ and $\mathrm{KGd}\left(\mathrm{WO}_{4}\right)_{2}, "$ Opt. Lett., vol. 22, pp. 1317-1319, 1997.

[15] X. Mateos, V. Petrov, M. Aguilo, R. M. Solé, J. Gavalda, J. Massons, F. Díaz, and U. Griebner, "Continuous-wave laser oscillation of $\mathrm{Yb}^{3+}$ in monoclinic $\mathrm{KLu}\left(\mathrm{WO}_{4}\right)_{2}$," IEEE J. Quantum Electron., vol. 40, no. 8 , pp. 1056-1059, Aug. 2004.

[16] J. Liu, U. Griebner, V. Petrov, H. Zhang, J. Zhang, and J. Wang, "Efficient continuous-wave and Q-switched operation of a diode-pumped $\mathrm{Yb}: \mathrm{KLu}\left(\mathrm{WO}_{4}\right)_{2}$ laser with self-Raman conversion," Opt. Lett., vol. 30, pp. 2427-2429, 2005.

[17] A. Brenier and G. Boulon, "Overview of the best $\mathrm{Yb}^{3+}$-doped laser crystals," J. Alloys Compound, vol. 323/324, pp. 210-213, 2001.

[18] A. Brenier, "A new evaluation of $\mathrm{Yb}^{3+}$-doped crystals for laser applications," J. Lumin., vol. 92, pp. 199-204, 2001.

[19] J. E. Hellström, S. Bjurshagen, V. Pasiskevicius, J. Liu, V. Petrov, and U. Griebner, "Efficient $\mathrm{Yb}: \mathrm{KGW}$ lasers end-pumped by high-power diode bars," Appl. Phys. B, vol. 83, pp. 235-239, 2006.

[20] M. C. Pujol, M. A. Bursukova, F. Güell, X. Mateos, R. Solé, J. Gavaldà, M. Aguiló, J. Massons, F. Díaz, P. Klopp, U. Griebner, and V. Petrov, "Growth, optical characterization, and laser operation of a stoichiometric crystal $\mathrm{KYb}\left(\mathrm{WO}_{4}\right)_{2}$," Phys. Rev. B, vol. 65, pp. 165121-1-165121-11, 2002.

[21] P. Klopp, V. Petrov, U. Griebner, V. Nesterenko, V. Nikolov, M. Marinov, M. A. Bursukova, and M. Galan, "Continuous-wave lasing of a stoichiometric Yb laser material: $\mathrm{KYb}\left(\mathrm{WO}_{4}\right)_{2}$," Opt. Lett., vol. 28, pp. 322-324, 2003.

[22] P. Klopp, V. Petrov, and U. Griebner, "Potassium ytterbium tungstate provides the smallest laser quantum defect," Jpn.J. Appl. Phys., vol. 42, pp. L246-L248, 2003.

[23] S. Erhard, J. Gao, A. Giesen, K. Contag, A. A. Lagatsky, A. Abdolvand, N. V. Kuleshov, J. Aus der Au, G. J. Spühler, F. Brunner, R. Paschotta, and U. Keller, "High power $\mathrm{Yb}: \mathrm{KGW}$ and $\mathrm{Yb}: \mathrm{KYW}$ thin disk laser operation," in OSA TOPS, vol. 56, Conf. on Lasers Electro-Optics, Tech Dig., Postconf. Edition. Washington, DC: Optical Society of America, 2001, pp. 333-334.

[24] S. R. Bowman, N. W. Jenkins, S. P. O'Connor, and B. J. Feldman, "Sensitivity and stability of a radiation-balanced laser system," IEEE J. Quantum Electron., vol. 38, no. 10, pp. 1339-1348, Oct. 2002. 
[25] A. Bouchier, G. Lucas-Leclin, F. Balembois, and P. Georges, "Intense laser emission at $981 \mathrm{~nm}$ in an ytterbium-doped $\mathrm{KY}\left(\mathrm{WO}_{4}\right)_{2}$ crystal," in $A d v$. Solid-State Photonics, OSA TOPS, vol. 98, C. Denman and I. Sorokina, Eds. Washington, DC: Optical Society of America, 2005, pp. 157-161.

[26] U. Griebner, S. Rivier, V. Petrov, M. Zorn, G. Erbert, M. Weyers, X. Mateos, M. Aguiló, J. Massons, and F. Díaz, "Passively mode-locked Yb:KLu( $\left(\mathrm{WO}_{4}\right)_{2}$ oscillators," Opt. Exp., vol. 13, pp. 3465-3470, 2005.

[27] H. Liu, J. Nees, and G. Mourou, "Diode-pumped Kerr-lens mode-locked Yb:KY $\left(\mathrm{WO}_{4}\right)_{2}$ laser," Opt. Lett., vol. 26, pp. 1723-1725, 2001.

[28] G. Paunescu, J. Hein, and R. Sauerbrey, "100-fs diode-pumped Yb:KGW mode-locked laser," Appl. Phys. B, vol. 79, pp. 555-558, 2004.

[29] P. Klopp, V. Petrov, U. Griebner, and G. Erbert, "Passively mode-locked Yb:KYW laser pumped by a tapered diode laser," Opt. Exp., vol. 10, pp. 108-113, 2002.

[30] F. Brunner, G. J. Spühler, J. Aus der Au, L. Krainer, F. Morier-Genoud, R. Paschotta, N. Lichtenstein, S. Weiss, C. Harder, A. A. Lagatsky, A. Abdolvand, N. V. Kuleshov, and U. Keller, "Diode-pumped femtosecond $\mathrm{Yb}: \mathrm{KGd}\left(\mathrm{WO}_{4}\right)_{2}$ laser with 1.1-W average power," Opt.Lett., vol. 25 , pp. 1119-1121, 2000.

[31] C. Courjaud, N. Deguil, and F. Salin, "High power diode-pumped Yb:KGW laser ultrafast laser," in OSA TOPS, vol. 73, Conf. Lasers Electro-Optics, OSA Tech. Dig. Washington, DC: Optical Society of America, 2002, pp. 501-502, Paper CThO3

[32] G. R. Holtom, "Mode-locked Yb:KGW laser longitudinally pumped by polarization-coupled diode bars," Opt. Lett., vol. 31, pp. 2719-2721, 2006.

[33] F. Brunner, T. Südmeyer, E. Innerhofer, F. Mourier-Genoud, R. Paschotta, V. E. Kisel, V. G. Shcherbitsky, N. V. Kuleshov, J. Gao, K. Contag, A. Giesen, and U. Keller, "240-fs pulses with 22-W average power from a mode-locked thin-disk $\mathrm{Yb}: \mathrm{KY}\left(\mathrm{WO}_{4}\right)_{2}$ laser," Opt. Lett., vol. 27, pp. 1162-1164, 2002.

[34] D. Nickel, C. Stolzenburg, and A. Giesen, "Ultrafast thin-disk $\mathrm{Yb}: \mathrm{KY}\left(\mathrm{WO}_{4}\right)_{2}$ regenerative amplifier with $200-\mathrm{kHz}$ repetition rate," Opt. Lett., vol. 29, pp. 2764-2766, 2004.

[35] A. Killi, A. Steinmann, J. Dörring, U. Morgner, M. J. Lederer, D. Kopf, and C. Fallnich, "High-peak-power pulses from a cavity-dumped Yb:KY $\left(\mathrm{WO}_{4}\right)_{2}$ oscillator," Opt. Lett., vol. 30, pp. 1891-1893, 2005.

[36] T. T. Basiev, A. A. Sobol, P. G. Zverev, L. I. Ivleva, V. V. Osiko, and R. C. Powell, "Raman spectroscopy of crystals for stimulated Raman scattering," Opt. Mater., vol. 11, pp. 307-314, 1999.

[37] A. A. Lagatsky, A. Abdolvand, and N. V. Kuleshov, "Passive Q switching and self-frequency Raman conversion in a diode-pumped $\mathrm{Yb}: \mathrm{KGd}\left(\mathrm{WO}_{4}\right)_{2}$ laser," Opt. Lett., vol. 25, pp. 616-618, 2000.

[38] A. S. Grabtchikov, A. N. Kuzmin, V. A. Lisinetskii, V. A. Orlovich, A. A. Demidovich, M. B. Danailov, H. J. Eichler, A. Bednarkiewicz, W. Strek, and A. N. Titov, "Laser operation and Raman self-frequency conversion in Yb:KYW microchip laser," Appl. Phys. B, vol. 75, pp. 795$797,2002$.

[39] V. E. Kisel, V. G. Shcherbitsky, and N. V. Kuleshov, "Efficient selffrequency Raman conversion in a passively Q-switched diode-pumped $\mathrm{Yb}: \mathrm{KGd}\left(\mathrm{WO}_{4}\right)_{2}$ laser," in Advanced Solid-State Photonics, OSA TOPS, vol. 83, J.Zayhowski, Ed. Washington, DC: Optical Society of America, 2003, pp. 189-192.

[40] S. N. Bagaev, S. M. Vatnik, A. P. Maiorov, A. A. Pavlyuk, and D. V. Plakushchev, "The spectroscopy and lasing of monoclinic Tm:KY $\left(\mathrm{WO}_{4}\right)_{2}, "$ Quantum Electron., vol. 30, pp. 310-314, 2000 (Transl.: Kvantovaya Elektron., vol. 30, pp. 310-314, 2000).

[41] A. A. Kaminskii, L. Li, A. V. Butashin, V. S. Mironov, A. A. Pavlyuk, S. N. Bagaev, and K. Ueda, "New stimulated emission channels of $\mathrm{Pr}^{3+}$ and $\mathrm{Tm}^{3+}$ ions in monoclinic $\mathrm{KR}\left(\mathrm{WO}_{4}\right)_{2}$ type crystals with ordered structure (R = Y and Gd), Jpn. J. Appl. Phys., vol. 36, pp. L107-L109, 1997.

[42] A. A. Demidovich, A. N. Kuzmin, N. K. Nikeenko, A. N. Titov, M. Mond, and S. Kück, "Optical characterization of Yb, Tm:KYW crystal concerning laser application," J. Alloys Compound, vol. 341, pp. 124-129, 2002.

[43] L. E. Batay, A. A. Demidovich, A. N. Kuzmin, A. N. Titov, M. Mond, and $\mathrm{S}$. Kück, "Efficient tunable laser operation of diode-pumped $\mathrm{Yb}$, Tm:KY $\left(\mathrm{WO}_{4}\right)_{2}$ around $1.9 \mu \mathrm{m}$," Appl. Phys. B, vol. 75, pp. 457-461, 2002.

[44] L. E. Batay, A. N. Kuzmin, A. S. Grabtchikov, V. A. Lisinetskii, V. A. Orlovich, A. A. Demidovich, A. N. Titov, V. V. Badikov, S. G. Sheina, V. L. Panyutin, M. Mond, and S. Kück, "Efficient diode-pumped passively Q-switched laser operation around $1.9 \mu \mathrm{m}$ and self-frequency Raman conversion of Tm-doped $\mathrm{KY}\left(\mathrm{WO}_{4}\right)_{2}$," Appl. Phys. Lett., vol. 81, pp. 29262928, 2002.
[45] S. Vatnik, E. Balashov, A. Pavljuk, E. Golikova, and A. Lyutetskiy, "Measurement of gain and evolution of photon avalanche efficiency in $10 \%$ Tm:KY $\left(\mathrm{WO}_{4}\right)_{2}$ crystal pumped by free-running Nd:YAG laser," Opt. Commun., vol. 220, pp. 397-400, 2003.

[46] S. M. Vatnik, A. P. Maiorov, A. A. Pavlyuk, and D. V. Plakushchev, "Spectroscopy and kinetics of the population of monoclinic $\mathrm{KYb}_{0.5} \mathrm{Y}_{0.43} \mathrm{Tm}_{0.07}\left(\mathrm{WO}_{4}\right)_{2}$ crystals pumped by a pulsed Nd:YAG laser," Quantum Electron., vol. 31, pp. 19-22, 2001 (Transl.: Kvantovaya Elektron., vol. 31, pp. 19-22, 2001).

[47] V. Petrov, F. Güell, J. Massons, J. Gavaldà, R. M. Solé, M. Aguiló, F. Díaz, and U. Griebner, "Efficient tunable laser operation of $\operatorname{Tm}: \operatorname{KGd}\left(\mathrm{WO}_{4}\right)_{2}$ in the continuous-wave regime at room temperature," IEEE J. Quantum Electron., vol. 40, no. 9, pp. 1244-1251, Sep. 2004.

[48] X. Mateos, V. Petrov, J. Liu, M. C. Pujol, U. Griebner, M. Aguiló, F. Díaz, M. Galan, and G. Viera, "Efficient 2- $\mu \mathrm{m}$ continuous-wave laser oscillation of Tm3+:KLu( $\left.\mathrm{WO}_{4}\right)_{2}$," IEEE J. Quantum Electron., vol. 42, no. 10, pp. 1008-1015, Oct. 2006.

[49] B. Ferrand, B. Chambaz, and M. Couchaud, "Liquid phase epitaxy: A versatile technique for the development of miniature optical components in single crystal dielectric media," Opt. Mater., vol. 11, pp. 101-114, 1999.

[50] M. Pollnau and Y. E. Romanyuk, "Optical waveguides in laser crystals," C. R. Phys., vol. 8, pp. 123-137, 2007

[51] Y. E. Romanyuk, I. Utke, D. Ehrentraut, V. Apostolopoulos, M. Pollnau, S. García-Revilla, and R. Valiente, "Low-temperature liquid phase epitaxy and optical waveguiding of rare-earth-ion doped $\mathrm{KY}\left(\mathrm{WO}_{4}\right)_{2}$ thin layers," J. Cryst. Growth, vol. 269, pp. 377-384, 2004.

[52] R. Solé, V. Nikolov, X. Ruiz, J. Gavaldà, X. Solans, M. Aguiló, and F. Díaz, "Growth of $\beta-\mathrm{KGd}_{1-x} \mathrm{Nd}_{x}\left(\mathrm{WO}_{4}\right)_{2}$ single crystals in $\mathrm{K}_{2} \mathrm{~W}_{2} \mathrm{O}_{7}$ solvents," J. Cryst. Growth, vol. 169, pp. 600-603, 1996.

[53] Y. E. Romanyuk, C. N. Borca, M. Pollnau, S. Rivier, V. Petrov, and U. Griebner, "Yb-doped $\mathrm{KY}\left(\mathrm{WO}_{4}\right)_{2}$ planar waveguide laser," Opt. Lett., vol. 31, pp. 53-55, 2006.

[54] A. Aznar, R. Solé, M. Aguiló, F. Díaz, U. Griebner, R. Grunwald, and V. Petrov, "Growth, optical characterization and laser operation of epitaxial Yb:KY $\left(\mathrm{WO}_{4}\right)_{2} / \mathrm{KY}\left(\mathrm{WO}_{4}\right)_{2}$ composites with monoclinic structure," Appl. Phys. Lett., vol. 85, pp. 4313-4315, 2004.

[55] F. Gardillou, Y. E. Romanyuk, C. N. Borca, R. P. Salathé, and M. Pollnau, "Lu, Gd co-doped $\mathrm{KY}\left(\mathrm{WO}_{4}\right)_{2}: \mathrm{Yb}$ epitaxial layers: Towards integrated optics based on $\mathrm{KY}\left(\mathrm{WO}_{4}\right)_{2}$," Opt. Lett., vol. 32, pp. 488-490, 2007.

[56] M. C. Pujol, X. Mateos, R. Solé, J. Massons, J. Gavaldà, X. Solans, F. Díaz, and M. Aguiló, "Structure, crystal growth and physical anisotropy of $\mathrm{KYb}\left(\mathrm{WO}_{4}\right)_{2}$, a new laser matrix," J. Appl. Cryst., vol. 35, pp. 108-112, 2002.

[57] S. Rivier, X. Mateos, V. Petrov, U. Griebner, Y. E. Romanyuk, C. N. Borca, F. Gardillou, and M. Pollnau, "Tm: $\mathrm{KY}\left(\mathrm{WO}_{4}\right)_{2}$ waveguide laser," Opt. Exp., vol. 15, pp. 5885-5892, 2007.

[58] J. A. Caird, S. A. Payne, P. R. Staber, A. J. Ramponi, L. L. Chase, and W. F. Krupke, "Quantum electronic properties of the $\mathrm{Na}_{3} \mathrm{Ga}_{2} \mathrm{Li}_{3} \mathrm{~F}_{12}: \mathrm{Cr}^{3+}$ laser," IEEE J. Quantum Electron., vol. 24, no. 6, pp. 1077-1099, Jun. 1988.

[59] U. Griebner and H. Schönnagel, "Laser operation with nearly diffractionlimited output from a Yb:YAG multimode channel waveguide," Opt. Lett., vol. 24, pp. 750-752, 1999.

[60] M. Pollnau, C. Grivas, L. Laversenne, J. S. Wilkinson, R. W. Eason, and D. P. Shepherd, "Ti:sapphire waveguide lasers," Laser Phys. Lett., vol. 4, pp. $560-571,2007$.

[61] A. Crunteanu, M. Pollnau, G. Jänchen, C. Hibert, P. Hoffmann, R. P. Salathé, R. W. Eason, C. Grivas, and D. P. Shepherd, "Ti:sapphire rib channel waveguide fabricated by reactive ion etching of a planar waveguide," Appl. Phys. B, vol. 75, pp. 15-17, 2002.

[62] C. Grivas, D. P. Shepherd, T. C. May-Smith, R. W. Eason, M. Pollnau, A. Crunteanu, and M. Jelinek, "Performance of $\mathrm{Ar}^{+}$-milled Ti:sapphire rib waveguides as single transverse mode broadband fluorescence sources," IEEE J. Quantum Electron., vol. 39, no. 3, pp. 501-507, Mar. 2003.

[63] V. Apostolopoulos, L. Laversenne, T. Colomb, C. Depeursinge, R. P. Salathé, M. Pollnau, R. Osellame, G. Cerullo, and P. Laporta, "Femtosecond-irradiation-induced refractive-index changes and channel waveguiding in bulk $\mathrm{Ti}^{3+}$ :sapphire," Appl.Phys. Lett., vol. 85, pp. 11221124, 2004.

[64] L. Laversenne, P. Hoffmann, M. Pollnau, P. Moretti, and J. Mugnier, "Designable buried waveguides in sapphire by proton implantation," Appl. Phys. Lett., vol. 85, pp. 5167-5169, 2004. 
[65] C. Grivas, D. P. Shepherd, T. C. May Smith, R. W. Eason, and M. Pollnau, "Single-transverse-mode Ti:sapphire rib waveguide laser," Opt. Exp., vol. 13, pp. 210-215, 2005.

[66] C. Grivas, D. P. Shepherd, R. W. Eason, L. Laversenne, P. Moretti, C. N. Borca, and M. Pollnau, "Room-temperature continuous-wave operation of Ti:sapphire buried channel-waveguide lasers fabricated via proton implantation," Opt. Lett., vol. 31, pp. 3450-3452, 2006.

[67] C. N. Borca, F. Zäh, C. Schnider, R. P. Salathé, M. Pollnau, and P. Moretti, "Optical planar waveguides in $\mathrm{KY}\left(\mathrm{WO}_{4}\right)_{2}$ formed by ion-beam implantation," in Proc. Int. Laser Phys. Workshop, Kyoto, Japan, 2005, p. 246, Book of Abstracts.

[68] C. N. Borca, F. Zäh, C. Schnider, R. P. Salathé, M. Pollnau, and P. Moretti, "Fabrication of optical planar waveguides in $\mathrm{KY}\left(\mathrm{WO}_{4}\right)_{2}$ by He-ion implantation," in Conf. Lasers Electro-Opt. Europe, Conf. Dig., Munich, Germany, 2005, Paper CE6-3-FRI

[69] C. N. Borca, Y. E. Romanyuk, F. Gardillou, M. Pollnau, M. P. Bernal, and P. Moretti, "Optical channel waveguides in $\mathrm{KY}\left(\mathrm{WO}_{4}\right)_{2}: \mathrm{Yb}^{3+}$," in Conf. Lasers Electro-Opt., Tech. Dig., Long Beach, CA, Washington, DC: Optical Society of America, 2006.

[70] C. N. Borca, V. Apostolopoulos, F. Gardillou, H. Limberger, M. Pollnau, and R. P. Salathé, "Buried channel waveguides in $\mathrm{Yb}$-doped $\mathrm{KY}\left(\mathrm{WO}_{4}\right)_{2}$ crystals fabricated by femtosecond laser irradiation," Appl. Surf. Sci., to be published.

[71] M. C. Pujol, X. Mateos, R. Solé, J. Massons, J. Gavaldà, F. Díaz, and M. Aguiló, "Linear thermal expansion tensor in $\operatorname{KRE}\left(\mathrm{WO}_{4}\right)_{2}(\mathrm{RE}=$ Gd, Y, Er, Yb) monoclinic crystals," Mater. Sci. Forum, vol. 378-381, pp. 710-715, 2001.

[72] M. C. Pujol, X. Mateos, A. Aznar, X. Solans, S. Surinach, J. Massons, F. Díaz, and M. Aguiló, "Structural redetermination, thermal expansion and refractive indices of $\mathrm{KLu}\left(\mathrm{WO}_{4}\right)_{2}, " J$. Appl. Crystallogr., vol. 39, pp. 230-236, 2006.

[73] R. Baets and P. E. Lagasse, "Calculation of radiation loss in integratedoptic tapers and Y-junctions,” Appl. Opt., vol. 21, pp. 1972-1978, 1982.

[74] F. Gardillou, Y. E. Romanyuk, M. Pavius, C. N. Borca, R. P. Salathé, and M. Pollnau, "Focused-ion-beam nano-structured rib channel waveguides in $\mathrm{KY}\left(\mathrm{WO}_{4}\right)_{2}$ for laser applications," in Proc. Int. Laser Phys. Workshop, Lausanne, Switzerland, 2006, p. 210, Book of Abstracts.

Markus Pollnau received the Diploma degree in physics from the University of Hamburg, Hamburg, Germany, in 1992, and the Ph.D. degree in physics from the University of Bern, Bern, Switzerland, in 1996.

He was a Research Fellow of the European Union at the University of Southampton, U.K. He was also a Postdoctoral Fellow at the University of Bern. In 1999, he joined the Swiss Federal Institute of Technology, Lausanne, Switzerland, where he was a "Profil" Research Fellow of the Swiss National Science Foundation. Since 2004, he has been with the MESA+ Research Institute, University of Twente, Enschede, The Netherlands, where he is a Full Professor and the Chair of the Integrated Optical Micro Systems Group. His current research interests include integrated optics, emphasizing the investigation and development of on-chip light generation and modulation as well as passive integrated structures in dielectric materials for applications in optical sensing, biomedicine, and telecommunication. He is the Coauthor of more than 200 technical contributions published in international journals and conferences.

Prof. Pollnau is a member of the Optical Society of America and the European Physical Society.

Yaroslav E. Romanyuk received the Graduate degree from the Department of Chemistry, Volyn State University, Lutsk, Ukraine, in 2002, and the Ph.D. degree from the Swiss Federal Institute of Technology, Lausanne, Switzerland, in 2005 .

In 2006, he received a Prospective Researcher Personal Fellowship from the Swiss National Science Foundation to work at the University of California, Berkeley. He is currently with the Lawrence Berkeley National Laboratory, Berkeley, CA. His current research interests include molecular beam epitaxy of intentionally doped III-V semiconductor alloys for lighting and photovoltaic applications.
Florent Gardillou received the B.S. degree of engineering in physics from the Ecole Nationale Supérieure de Physique de Grenoble, Grenoble, France, in 2002, and the M.S. and Ph.D. degrees in photonics from the Institut National Polytechnique de Grenoble, Grenoble, in 2002 and 2005, respectively.

He has been engaged in the study of hybridization of active optical functions on ion-exchanged passive glass substrates thanks to the wafer bonding technology. He was a Postdoctoral Fellow at the Advanced Photonics Laboratory, Ecole Polytechnique Fédérale de Lausanne, Switzerland, where he was engaged in the growth of novel thin epilayers of $\mathrm{KY}\left(\mathrm{WO}_{4}\right)_{2}$ doped with rare-earth ions for high-power solid-state laser applications. In 2006, he joined the Amplifiers and Lasers R\&D Group, Teem Photonics, Meylan, France.

Camelia N. Borca received the Bachelor's degree in physics from the University of Bucharest, Bucharest, Romania, in 1994, and the Ph.D. degree from the University of Nebraska at Lincoln, Lincoln, in 2001.

She was a Postdoctoral Fellow at JILA, University of Colorado, Boulder In 2004, she joined the Institute of Imaging and Applied Optics, Ecole Polytechnique Fédérale de Lausanne, where she was engaged in developing novel oxide channel waveguide structures. Currently, she is a Beamline Scientist at the Swiss Light Source, Paul Scherrer Institut, Villigen, Switzerland. Her research interests include thin-film growth, surface characterization, and optical and spectroscopic characterization of thin-film materials. She is the Coauthor of more than 55 papers published in journals and conference proceedings.

Uwe Griebner received the Ph.D. degree in physics from the Technical University of Berlin, Berlin, Germany, in 1996.

Since 1992, he has been with Max-Born-Institute for Nonlinear Optics and Ultrafast Spectroscopy, Berlin, Germany, where he is engaged in diode-pumped solid-state lasers, fiber lasers, waveguide lasers, microoptics, microoptics for special resonators, and ultrafast lasers. His current research interests include ultrafast diode-pumped solid-state lasers and amplifiers applying new active materials and the use of microoptical components for femtosecond beam-shaping.

Simon Rivier was born in Bristol, U.K., in 1978. He received the M.Sc. degree from the Swiss Federal Institute of Technology, Lausanne, Switzerland, in 2003. $\mathrm{He}$ is currently working toward the $\mathrm{Ph} . \mathrm{D}$. degree on diode-pumped solid-state lasers with new active materials at Max-Born-Institute for Nonlinear Optics and Ultrafast Spectroscopy, Berlin, Germany.

Valentin Petrov was born in Plovdiv, Bulgaria, in 1959. He received the M.Sc. degree in nuclear physics from the University of Sofia, Bulgaria, in 1983, and the Ph.D. degree in optical physics from Friedrich-Schiller-University, Jena, Germany, in 1988.

He joined Max-Born-Institute for Nonlinear Optics and Ultrafast Spectroscopy, Berlin, Germany, in 1992. His current research interests include ultrashort light pulses, laser physics, and nonlinear optics. He is the Coauthor of about 150 papers published in scientific journals. 